\title{
Filantropía democrática y sentimientos morales
}

\author{
HELENA BÉJAR \\ Universidad Complutense de Madrid
}

\begin{abstract}
Resumen. El siguiente trabajo analiza los sentimientos morales dentro del voluntariado como una práctica cívica que enlaza el individualismo, eje axial de la cultura contemporánea, y el altruismo, entendido como un comportamiento extraordinario, tanto social como moralmente. En concreto, se estudian las motivaciones del voluntariado formal, dejando de lado la ayuda informal y espontánea. Aparecen tres discursos que se presentan como tipos ideales, aunque en todos ellos se combinen la dicotomía altruismo/egoísmo. Tales discursos son el individualista, el cristiano y el cívico, y expresan los lenguajes morales contemporáneos que hablan sobre los valores en torno a la vinculación social y los sentimientos morales a ella asociados.
\end{abstract}

Abstract. The following article analizes the moral sentiments attached to volunteer work as a civic practice which links individualism and altruism. I consider individualism as the moral center of contemporary culture, whereas altruism is an extraordinary behaviour, both in the moral and the social sense. I have studied the motivations of formal volunteerism, leaving aside informal help. I have found three discourses that have been considered as ideal types, even though in all of them individualism and altruism are intertwined. The so-called individualistic language, the Christian one and the civic one express the contemporary moral languages, which contain a specific conception of the social ties and the moral sentiments that are adscribed to it.

\section{Introducción}

¿Por qué se ayuda a un extraño? ¿Existe todavía la compasión, en tanto que sentimiento moral que enlaza a los hombres? ¿Cuál es la batería de afectos que sostienen nuestro concepto de libertad y los valores que guían la acción social? Éstas son algunas de las preguntas que se pueden responder a través del análisis del voluntariado actual como una forma peculiar de vinculación social. Las páginas siguientes presentan los resultados de una investigación sociológica con metodología cualitativa sobre lo que llamo «mapa de motivos» del voluntariado en la Comunidad de Madrid. A lo largo de casi dos años se realizaron doce grupos de discusión y veintidós entrevistas en profundidad a voluntarios de la Comunidad Autónoma de Madrid, así como diez entrevistas semidirectivas a responsables de diversas Organizaciones No Gubernamentales.

${ }^{1}$ Para la idea de motivos me he basado en el clásico artículo de C. Wright Mills, «Situated actions and the vocabulary of motives», en I. Horowitz (ed.), Power, Politics and People. The Collected Essays of C. Wright Mills, Nueva York, Oxford, Oxford University Press, 1963. 
La investigación pretendía averiguar cuáles son las razones del altruismo organizado, esto es, del voluntariado formal adscrito a organizaciones-. Más concretamente, me interesaba el voluntariado social, que ayuda a lo que se pueden considerar «extraños próximos» (inmigrantes, enfermos, ancianos, etc.) frente al voluntariado de cooperación al desarrollo, que se encarga de los «extraños lejanos», es decir, de la pobreza y los desastres naturales de los países del Tercer Mundo. En mi opinión, es el voluntariado social el que intenta paliar las necesidades del Otro cercano - entendiéndose esta cercanía tanto espacial como simbólicamente- y el que más habla de nuestra condición moral, a pesar de que es el voluntariado de cooperación al desarrollo el que ha acaparado hasta ahora la atención tanto institucional como mediática.

¿Significa el voluntariado una recuperación de la virtud, no sólo en un sentido moral, sino también político, como retorno a la participación en la esfera pública? O, por el contrario, iestá el altruismo organizado imbuido del individualismo que ha gobernado los últimos decenios de la cultura occidental? Y si éste es el caso, ¿cuál es su dimensión colectiva? El voluntariado es una actividad que se desarrolla en el ámbito de la sociedad civil, entendida como área de la gestación de los valores. Más en concreto, el voluntariado forma parte del llamado tercer sector o «sector independiente», tanto respecto del Estado — como esfera de la coacción- como del mercado - como ámbito del interés-. Pues bien, dentro de la sociedad civil (que la tradición de pensamiento opuesta a la liberal, la republicana, prefiere llamar sociedad política) tiene lugar el voluntariado. Considero a éste como una metáfora de la gestación y expresión de unos valores colectivos que oscilan entre el egoísmo (trasunto moral del individualismo, que es un fenómeno sociopolítico) y el altruismo. Mi objetivo no era analizar el origen, el desarrollo o el futuro del voluntariado, sino más bien desentrañar el entramado social que genera. Si éste se sostiene por un nuevo comunitarismo o, por el contrario, está hecho de una urdimbre de valores de raíz individualista. En pocas palabras, se trataba de investigar el porqué de la ayuda. Hablar de los motivos de una conducta - el voluntariado- conlleva analizar los códigos, es decir, los conjuntos de racionalizaciones que dicen de la configuración social, política y moral contemporánea. De la explicitación de las razones se extrae, entre otros elementos, la imagen de la comunidad como propiedad simbólica colectiva, la concepción de la ciudadanía como participación, y los ideales de libertad y vinculación.

De ahí la pertinencia de una metodología cualitativa, que analiza los discursos de los sujetos sociales y, en el caso que nos ocupa, del conjunto de sentimientos morales que anidan en la peculiar vinculación social que supone el voluntariado. Mi hipótesis es que los motivos son importantes porque orientan la acción personal y social y porque discriminan entre sus posibles objetos. Además porque, al verbalizarlos, influyen en los demás. Creo que el motivo de la ayuda es importante porque determina el tipo de vinculación en tiempo y en implicación emocional que se establece con el objeto de auxilio. El análisis 
cualitativo permite desbrozar los lenguajes genéricos que enmarcan el voluntariado como acción social. Dichos lenguajes forman parte de una tradición, entendida como un modelo de comprensión y evaluación que las sociedades forjan a lo largo del tiempo. Las tradiciones son razonamientos elaborados sobre las relaciones sociales y las instituciones que forman las comunidades humanas. En este caso me interesaba la percepción y evaluación por parte de los sujetos entrevistados en relación a la esfera pública y la privada, en cuya intersección se halla el voluntariado.

En relación al mismo distingo dos lenguajes genéricos ${ }^{2}$. Por una parte, el llamado lenguaje primario, dominante y hegemónico, que entronca con la tradición del individualismo liberal. En sus dos versiones, del individualismo utilitario y el expresivo, el lenguaje primario se fundamenta en un relativismo moral y un emotivismo enraizados ya en el sentido común. Dicho lenguaje se encuentra prioritariamente en los voluntarios jóvenes - entre veinte y veinticinco años- que forman el grueso del ejército de la nueva filantropía. Por otra parte, está el llamado lenguaje secundario, tácito y en retroceso, que defiende una moral fuerte anclada en la virtud. Ésta puede ser moral, y se encuentra en el discurso del voluntariado tradicional, de raigambre cristiana, formado por amas de casa - de edades comprendidas entre los cincuenta y sesenta y cinco años-. Mas la virtud puede tener un sentido político, identificada con la participación ciudadana, y se halla, aunque de manera muy matizada, en el discurso de los profesionales - entre treinta y cinco y cincuenta y cinco años-. A continuación expondré los argumentos principales de los discursos mencionados, haciendo especial hincapié en los sentimientos morales que anudan -o desmembran - los vínculos sociales, uno de los cuales es la nueva filantropía.

\section{El lenguaje primario del individualismo}

En su estudio seminal sobre la democracia americana, Alexis de Tocqueville esbozó los rasgos del altruismo democrático. Él observó en los Estados Unidos el laboratorio donde se estaba gestando el porvenir de la sociabilidad moderna. Basado en la igualdad, el nuevo altruismo descansa en una «benevolencia tranquila» consecuencia de una suave identificación con el prójimo. Los hombres de la democracia, esto es, de la modernidad, se ven unos a otros como semejantes, como seres con los que es fácil la adhesión: «Los hombres de las democracias modernas muestran naturalmente piedad los unos por los otros. Al tener relaciones frecuentes y fáciles entre sí no se irritan fácilmente; es natural que se ayuden mutuamente en sus necesidades. Eso es lo que sucede en los Estados Unidos. En las democracias raramente se conceden grandes favores

${ }^{2}$ En lo que respecta a la noción de tradición, así como para la de lenguaje primario y secundario, he seguido a R. Bellah et al., en Hábitos del corazón, Madrid, Alianza Editorial, 1989. 
pero se hacen constantemente buenos oficios. Es raro que un hombre se muestre sacrificado, pero todos son serviciales» ${ }^{3}$. La piedad de la que se habla aquí no es la compasión cristiana — que veremos más adelante-, sino una suave empatía que supone ponerse en el lugar del otro. La ayuda que se prestan los hombres es fruto más de una coexistencia prolongada que de la entrega sentimental. La igualdad de condiciones acerca a los hombres y provee de una moral extendida de ayuda mutua basada en la reciprocidad. Ello no quiere decir que los hombres sean mejores que en la aristocracia, tipo ideal de una desigualdad que albergaba sentimientos extremos: grandes crueldades convivían con intensas devociones, así como el abuso de poder con la protección sobre el rango inferior. Por el contrario, la democracia instaura una sociabilidad templada basada en la anticipación de la necesidad del otro, en una previsión racional de la ayuda que promueve un cuidado diario compatible con la indiferencia: «No es que se interesen profundamente en su suerte, pues si por casualidad resultan inútiles los esfuerzos que hacen por socorrerles, les olvidan pronto y vuelven a sí mismos, pero se ha formado entre ellos una especie de acuerdo tácito y casi involuntario por el cual cada uno debe a los demás un apoyo momentáneo que a su vez podrá reclamar para sí» ${ }^{4}$. Así, la ayuda que engendra la igualdad no es tanto la entrega apasionada a la necesidad de un semejante específico como un hábito compatible con una indiferencia de fondo. Puesto que los hombres de las democracias son $-\mathrm{O}$ al menos, se sienten - iguales, llegan a hacerse intercambiables, incluso en ese auxilio que requieren antes o después y que se presta como una ley latente de la convivencia. Por ello, altruismo democrático es compatible con el individualismo, con ese olvido fácil del otro y ese retorno a uno mismo que anuncia Tocqueville. Así, en la filantropía democrática confluyen una vaga generosidad, una benevolencia difusa y una racionalidad que se adelanta a la propia necesidad. El fundamento del altruismo moderno no es, pues, el sentimiento, cuyo valor nuclear es la compasión, sino una racionalidad sostenida por la reciprocidad. Como veremos, ésta se alimenta de argumentos psicológicos que desplazan la moralidad de la filantropía democrática. Tal es el caso de la ayuda a los extraños cercanos, a esos que la igualdad de condiciones aproxima física y socialmente. Veamos lo que sucede con los extraños lejanos, con la necesidad que la llamada cooperación para el desarrollo quiere paliar.

El humanitarismo organizado forma parte de la llamada política de la vida, propia de una sociedad postmaterialista ${ }^{5}$ : «Cuando hay objetivos que están conseguidos, la lucha se dirige hacia otro sitio: la ecología y la solidaridad

\footnotetext{
A. de Tocqueville, La democracia en América, vol. 2, Madrid, Aguilar, 1989, p. 218, nota .

${ }^{4}$ Op. cit., pp. 218-219.

${ }^{5}$ La expresión "política de la vida» se encuentra en A. Giddens, Modernidad e identidad del yo: el yo y la sociedad en la época contemporánea, Barcelona, Península, 1995. En cuanto a la idea de los valores postmaterialistas se remite al ya clásico — aunque decepcionante- libro de R. Inglehart, El cambio cultural en las sociedades industriales avanzadas, Madrid, CIS/Siglo XXI, 1991.
} 
en el Tercer Mundo» (José, treinta y seis años, Médicos Mundi). Quizá sea ese desplazamiento desde la clásica política de la emancipación, centrada en lo social, hacia la política de la vida o política generativa - como la llama Bellah- que gira en torno a lo cultural y en la que la desigualdad se ha transformado en exclusión, lo que desencadena la crítica de los voluntarios jóvenes.

Éstos acusan al voluntariado de no ser más que una moda. Más concretamente, el reproche se dirige al «boom» de las ONG de cooperación al desarrollo, actividad que se opone valorativamente al voluntariado social, y ello en varios planos. En primer lugar, se enfrenta una actividad extraordinaria, el viaje al Tercer Mundo, a una ordinaria, el socorro callado y continuo con los más necesitados. En segundo lugar, los voluntarios oponen la atención otorgada por los medios de comunicación al voluntariado de cooperación al desarrollo, que han hecho del altruismo una «moda», término unánimemente denostado. Contra esta filantropía espectacular se yergue el voluntariado social, discreto y particular, producto de la buena voluntad de individuos concretos, huérfanos del apoyo institucional que su tarea merecería. En tercer lugar, los discursos confrontan la alusión velada al principio del placer que conlleva la aventura de viajar a tierras lejanas con el principio de realidad que supone el contacto con la desventura de los más necesitados.

Así, el voluntariado de cooperación al desarrollo, que ha hecho visible y ha dado a conocer la ayuda a extraños, ha producido un altruismo indoloro que satura la sensibilidad de los espectadores de los mal llamados desastres humanitarios. El resultado es la trivialización de la necesidad (el hambre o la pobreza extremas) y la producción de una información obscena por demasiado explícita: «El Tercer Mundo es otra cosa que ese niño flaco y lleno de moscas. O la madre negra y un niño mamando de un pecho vacío» (Fernando, veinte años, Solidarios para el Desarrollo, mendigos). Al cabo se produce la indiferencia, forma de socialización negativa propia de la modernidad. Y se podría hablar incluso de antipatía (un mecanismo psicosocial de defensa ante un estímulo demasiado intenso) hacia esos desgraciados que nos interrumpen a diario el almuerzo o la cena demandando auxilio.

La oposición a la moda del voluntariado y a la explosión de las ONG entronca con la distancia que los jóvenes voluntarios tienen respecto a los mecanismos que hacen de la ayuda personal una actividad social. En primer lugar, se critica la financiación de las organizaciones del cuidado. Ello se aplica, primero, a la privada, con el argumento de la contaminación (ciertas firmas como Fortuna o Benetton, nada inocentes, se enriquecen prestando su marca a ciertas organizaciones); pero también a la financiación pública, con el argumento de la dependencia (el voluntariado «se apacigua» si está apegado a subvenciones estatales). Mas, si se reconoce al mismo tiempo que las campañas publicitarias azuzan las conciencias, ya que los voluntarios y los socios son pocos para sufragar las organizaciones, cabe preguntar cuál sería la fuente adecuada de sostén económico. 
En segundo lugar los voluntarios jóvenes critican la formalización — «la burocracia» - con el argumento de la rigifidicación: la ayuda se inscribe en una ONG y ésta se transforma en «un pulpo con su cabeza y unos tentáculos que no hacen más que obedecer». Es entonces cuando se pierde la idea del voluntariado como... ¿Cómo qué? Se diría que un vago impulso propio de una personalidad altruista poco definida, o como mucho como un comportamiento imitativo («como la onda que provoca la piedra en un río») que desafía todo corsé organizacional. Por otra parte, la crítica a la formalización hace que se perciba al voluntario como un «primo» que sirve a los intereses del Estado, enemigo ubicuo que se aprovecha de la buena voluntad de la gente para paliar sus insuficiencias. En este sentido las ONG colaboran en esta estafa.

En tercer lugar, los jóvenes critican la politización del voluntariado. Éste se produce tanto desde la entronización institucional del voluntariado como desde la propuesta de incentivos selectivos para animar el impulso solidario: el pago a los voluntarios, la provisión de un carnet y un seguro, el cumplimiento de la Prestación Social Sustitutoria (hoy ya extinguida pero en funcionamiento cuando se realizó la investigación) son formas de atraer a un «gorrón» que sólo quiere sacar beneficios sociales del voluntariado. Éste, abundando en lo dicho más arriba, debería ser un impulso puro, con motivos virtuosos no manchados de interés. Por el contrario, el voluntario que acepta los incentivos selectivos se ve no sólo como un gorrón, sino también como un traidor a una Causa inconcreta y elevada, paradójicamente desgajada del compromiso que supone la pertenencia a una organización ${ }^{6}$. La gratuidad que define al voluntariado ideal alcanza todos los canales institucionales, incluyendo la inclusión del mismo en la enseñanza, secundaria y universitaria. A pesar de que muchos jóvenes reconocen haberse iniciado en el voluntariado a través de sus prácticas escolares, tachan de «jugada maestra del Estado» el intento de transmitir el altruismo a través de la educación. Es menester subrayar este rechazo porque supone poner trabas al vínculo cívico que se establece entre costumbres morales (lo que Montesquieu y Tocqueville llamaban mores) y las leyes (el proyecto de gobierno de iniciar a los niños en una práctica ciudadana). La concatenación entre gobierno, costumbres y leyes es una de las ideas madre del republicanismo, tradición contraria al liberalismo y que valora la participación como forma primera de realización humana. Frente a la neutralidad valorativa del liberalismo, el republicanismo cree que se hacen buenos ciudadanos inculcándoles buenas costumbres a través de una buenas leyes. Pero cuando el gobierno se entiende como un enemigo no cabe esa interrelación entre los tres vértices del triángulo virtuoso republicano.

La triple crítica a la financiación, a la formalización y a la politización de las organizaciones de ayuda muestran la profunda desconfianza institucional

${ }^{6}$ Los conceptos de primo, gorrón e incentivos selectivos provienen de la obra ya clásica de M. Olson, The Logic of Collective Action, Cambridge University Press, 1971. 
de los voluntarios jóvenes, que tienen una concepción conspirativa de la política como un mundo extraño y enemigo. Embargados de un espontaneísmo que hace muy difícil la transmisión y por ende la perduración de la acción voluntaria, y carentes de lenguaje político que enmarque el voluntariado en una sociedad política hecha una ciudadanía consciente que debe crecer, los voluntarios caen, sin saberlo, en el imaginario liberal que identifica la política con la Administración y el Estado, olvidando que esa esfera social que oponen a la política puede ser una sociedad política en la que el voluntariado sea una pieza clave.

La desafección hacia la política marca la versión radical del discurso juvenil, mientras que su versión moderada incide en la naturaleza imitativa del altruismo. En este sentido, el voluntario expande con su mero ejemplo el impulso solidario, a modo de estandarte de la virtud u hombre anuncio. Esta metáfora enlaza con el voluntariado como manifestación de la democracia directa. En ella entra tanto la idealización de lo local — «la calle»— como de la transmisión directa — «boca a boca»- del ejemplo. Ello entronca con la insistencia en la «sensibilización», una consigna de las ONG que los voluntarios han incorporado a sus discursos, que ha sustituido a la concienciación (propia de la política de la emancipación), que aludía a un convencimiento moral que opera más a través de la razón que de los sentimientos.

Una vez analizada la trama apolítica del discurso juvenil, pasaré a la urdimbre moral que teje la acción voluntaria. Para ello esbozaré los rasgos principales de tres modelos de conducta que articulan el voluntariado y hablan de las motivaciones que lo impulsan ${ }^{7}$. En primer lugar, tenemos el modelo terapéutico, que articula una defensa psicológica del cuidado. Nuestros voluntarios se hacen eco de dicho modelo cuando repiten las consignas de las ONG, que funcionan como guiones, es decir, formularios que, una vez aprendidos, informan modelos de acción. He descubierto dos mandatos, a saber, el distanciamiento afectivo y la educación en la autonomía. Ambas producen en los voluntarios una fuerte ambivalencia moral, que la sociología define como el choque entre expectativas incompatibles que, con carácter normativo, se asignan a las actitudes, creencias o comportamientos ligados a una posición o estatus ${ }^{8}$. En este caso, el de voluntario, al que la organización adiestra en la práctica de la llamada distancia de rol. En tanto que perteneciente a una organización, el voluntario debe embridar su simpatía hacia el objeto de ayuda a la vez que le enseña las bondades de la autosuficiencia. No voy a tratar aquí de distinguir los conceptos de autonomía y autosuficiencia, que se solapan en el discurso de los voluntarios; tan sólo subrayar su importancia y su conexión con el ideal de libertad negativa. Concepto clave en la configuración ideológica liberal, la libertad negativa es una libertad «frente a»o «con respecto a» y enlaza con un concepto espacial

\footnotetext{
${ }^{7}$ Los tres modelos que enmarcan las legitimaciones del voluntariado están inspirados en el magnífico libro de R. Wuthnow, Actos de compasión, Madrid, Alianza Editorial, 1996. Por mi parte, he adaptado las conclusiones de Wuthnow a los discursos de los entrevistados.

${ }^{8}$ R. K. Merton, Ambivalencia sociológica y otros ensayos, Madrid, Espasa Calpe, 1980.
} 
de la acción social. Los voluntarios mencionan la necesidad de «no meterse en el territorio» de quienes cuidan.

La metáfora del territorio muestra cómo la cautela inspira el trato con el drogadicto (que, se afirma, tiende a abusar de la confianza), el enfermo o el anciano (seres que, en su carencia o en su soledad, son intrínsecamente dependientes, algo que se silencia). Asimismo, la reserva (respecto a darles el número de teléfono o a verlos fuera del horario previsto) y la distancia, sentimientos morales que se enlazan con la noción de privacidad como esfera ideal de autonomía y autodesarrollo. La defensa por parte del voluntario de dicha esfera y la creencia del deber de estimular la autonomía del ayudado refuerzan una empatía limitada, una implicación sostenida como modelo de la conducta voluntaria.

La cuestión es si es posible una compasión limitada, o si ésta es una contradicción en los términos. Adam Smith en La teoría de los sentimientos morales entendía el mecanismo de la empatía como un complejo mecanismo de identificación con el otro, un «cambio imaginario» que implica comprender la situación o las circunstancias concretas del prójimo. Para ello predicaba la templanza y la mesura, sobre todo en la demostración de la aflicción, que será tanto más difícil de comprender cuanto más intensa sea, sobre todo si es una desgracia. El autodominio es una virtud de raigambre estoica que se debe practicar cuando se trata de relatar una enfermedad, por ejemplo. Lo que Smith llama self-mastery confiere dignidad de carácter y, además, facilita la sociabilidad, que descansa en pasiones tibias. Así, una «estima fría» anuda los vínculos de la sociedad comercial que Smith teoriza. Pero el autocontrol emocional que predican las ONG y que los jóvenes voluntarios suscriben es otra cosa. A mi juicio, tiene que ver menos con un estoicismo de nuevo cuño que con un supervivencialismo propio de la cultura individualista que el liberalismo ha entronizado. El individualismo democrático aparta la implicación por lo colectivo; también disuelve la implicación profunda con el otro, que se vive como un potencial invasor de la propia esfera.

Tras el modelo terapéutico, en segundo lugar se descubre en el discurso de los voluntarios jóvenes el modelo de crecimiento. Según éste, el ejercicio del altruismo hace crecer por dentro tanto al que lo practica como al beneficiario de la ayuda. El crecimiento interno se expresa vívidamente a través de la metáfora de la musculatura: uno ejerce el cuidado a los extraños como quien ejercita sus músculos, y se siente mejor cuanto más fuerte se nota, sentimiento de satisfacción que le impulsa a continuar y a veces a redoblar el esfuerzo. Pero el ejercicio del auxilio no se refleja sólo en uno mismo, sino que lleva también a hacer crecer al otro. El voluntario aparece como una especie de partero de las potencialidades que al necesitado se le atribuyen, según lo que llamo el principio de capacitación universal. La fe contemporánea en el valor de la autosuficiencia hace creer a los voluntarios que todos, incluso seres tan desvalidos como los ancianos o los minusválidos, tienen «capacidades». Se llega 
a decir que los niños mongólicos han de aprender a «demandar cariño», como si hubieran de mudar su necesidad por una autonomía bien dirigida.

Por su parte, el principio de la capacitación universal lleva a dos paradojas. En primer lugar, la imposibilidad de una compasión en sentido fuerte, en su sentido etimológico de «sufrir con» el otro. «No ganas nada con estar llorando tres días» (Alicia, veintitrés años, Proyecto Hombre, presos). La compasión profunda se entiende como «masoquismo», frente a la aprobación de un sentimiento de empatía leve, base de una ayuda funcional. En segundo lugar, la atribución universal de potencialidades internas y liberadoras conduce a la negación de la necesidad, el reconocimiento de la cual debería fundar el voluntariado. También de la desigualdad (que es un término que no sale apenas en los discursos, ni siquiera en los más radicales, sustituido por la más templada «exclusión»), sea ésta física o social. La insistencia en que nadie es «un pobrecito» (ni los ancianos abandonados en residencias, ni los mendigos enajenados, ni los enfermos de Alzheimer) borra la condición de víctimas (de una sociedad individualista e injusta, de una familia egoísta, etc.) y la de culpa o responsabilidad, individual o colectiva. Una vez que la víctima ha sido borrada, también se ha borrado el daño y la atribución de éste a agentes sociales. Así, desde un discurso psicologista (el de los voluntarios, que parece una obediente reproducción de las consignas organizacionales) que recalca «las potencialidades internas» y el imperativo de la autosuficiencia, el razonamiento social y político de las raíces de la desigualdad y la exclusión desaparece. O lo que es lo mismo, el lenguaje primario del individualismo - expresivo en este caso- ahoga el secundario que debería hablar de responsabilidades y remedios colectivos. Los dos modelos anteriores expresan la práctica de un altruismo endocéntrico, que subraya la satisfacción personal que se deriva de la ayuda, de la gratificación interna de cuidado al extraño ${ }^{9}$.

Mientras que los dos anteriores modelos suscriben una defensa psicológica de la ayuda, el tercer y último modelo, el del intercambio, apunta a una defensa sociológica de la misma que trasciende el lenguaje primario del individualismo. Alguien define al voluntariado como «la prestación de un bien o un servicio sin garantía de retorno». Los voluntarios hacen gala de una modestia exagerada, al insistir que la suya es una labor nada extraordinaria en lo moral, contra lo que generalmente se cree. Por el contrario, los soldados de la ayuda subrayan lo que se suele llamar altruismo recíproco, propio de una lógica utilitaria que poco tiene que ver con la compasión, con un sentimiento profundo de identificación y de implicación con los males ajenos. El que ayuda reconoce que «gana» algo. Sobre todo una ampliación de la tolerancia hacia el otro distinto, y ya sabemos del valor incuestionable de la tolerancia en el imaginario liberal,

${ }^{9}$ La oposición entre altruismo endocéntrico y exocéntrico se puede ver en Jerzy Karylowksi en «Two types of altruistic behavior: doing good to feel good or to make the other feel good», en V. J. Derlega y J. Grzelak (comps.), Cooperation and Helping behavior. Theories and Research, Nueva York, New York Academic Press, 1982. 
aunque se solape con la indiferencia, algo siempre posible por las paradojas analizadas más arriba. Si el voluntario gana madurez y tolerancia, ¿qué gana el ayudado? Compañía, se podría pensar, cariño, compasión. Mas no es éste el capital que los jóvenes mencionan. El altruismo recíproco se dice de nuevo psicológicamente: lo que gana el ayudado (en términos de individualismo utilitario) o se da (siguiendo el modelo del don) es «aumentar su autoestima». Ésta no es equivalente a la dignidad - usando el lenguaje secundario de la moralidad-, sino más bien el reconocimiento de sus capacidades, como si el ayudado tuviera también una musculatura que fortalecer.

Frente a la idea de que el voluntariado es un don sin retorno, puede decirse qué don vuelve bajo la forma del llamado altruismo de participación, que defiende que el descubrimiento de que uno se siente bien haciendo el bien contribuye a seguir haciendo el bien ${ }^{10}$. «Tú no le puedes quitar el derecho a sentirse bien a un tío por ayudar», dice un joven. El solapamiento entre sentimientos, derechos y acción social indica el peso del individualismo emotivista. Y es que el altruismo de participación se podría entender en clave social, siendo el voluntario un miembro de un todo en el que se coopera y se mejora. Para ello las ONG tendrían que insistir en el valor de la interdependencia. También en la metáfora de la cadena de ayuda donde cada uno es «un eslabón», un «granito de arena» en un desierto que todos podemos poblar. Pero no creo que dicha cadena se forme de piezas anónimas.

En efecto, las organizaciones insisten en impedir la conciencia de unicidad de los voluntarios, que no deben pasar demasiado tiempo con sus ayudados para que no se desarrollen vínculos personales. A mi juicio, la distancia de rol será muy buena para preservar los sentimientos fríos, pero impide el desarrollo de vínculos durables y, desde luego, una compasión profunda hecha de tiempo y compañía con una persona con quien puedes contar. El sentimiento fuerte de la certeza — por parte del objeto de ayuda- y del cariño — por parte del voluntario- no se contemplan. El imperativo de la autosuficiencia y la autocapacitación funcionan como frenos a un voluntariado del que resulte un vínculo de amistad y compromiso. La metáfora orgánica de que somos como un cuerpo de órganos interdependientes — repetida por los voluntariosno se puede realizar si se piensa que cada miembro es sustituible y ha de cumplir sólo una función temporal. Lejos de esta empatía controlada está el discurso de las amas de casa, que articulan el segundo lenguaje.

${ }^{10}$ He traducido por «altruismo de participación» el llamado nesting altruism, esbozado por J. Mansbridge en «On the contested nature of the public good», en Walter W. Powell y Elisabeth S. Clemens (comps.), Private Action and the Public Good, New Haven y Londres, Yale University Press, 1998. 


\section{El lenguaje secundario del cristianismo}

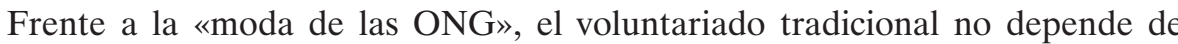
campañas publicitarias ni de entusiasmos mediáticos efímeros. El detonante de la acción de ayuda suele ser la familiaridad con el dolor ajeno (sobre todo la enfermedad de un familiar o «el trauma» que causa la muerte de una persona próxima), lo que predispone a experimentar sentimientos fuertes para ayudar al débil. Si el valor principal de la configuración individualista era la independencia (y sus derivados, la autosuficiencia y la autorrealización), el eje axial del discurso cristiano es, a mi juicio, la caridad, que tiene en la compasión su sentimiento moral más importante y en la vocación la motivación más llamativa.

Entre los rasgos de una personalidad altruista con rasgos cristianos se pueden destacar tres elementos. Primero, un espíritu de curiosidad o «disposición al descubrimiento» (que no es patrimonio de los cristianos y que aparece como una suerte de virtud social mencionada repetidas veces) que facilita la salida del ensimismamiento y el interés por lo social, o al menos por lo que le sucede al otro. (No olvidemos que el individualismo democrático se caracteriza por la reclusión en el universo privado y la exclusión del mundo exterior y extraño a la propia familia o amigos). En segundo lugar, la humildad y la modestia, una insistencia en quitar importancia a la labor realizada, algo genérico entre los voluntarios y que cobra un valor especial entre los cristianos por ser una enseñanza de los Evangelios. En tercer lugar, un espíritu de entrega y de generosidad alimentado por una vitalidad y un voluntarismo muy intensos que no existen en el discurso individualista, donde predominan los valores fríos. Dicha actitud lleva a pergeñar la comparación del voluntariado con la maternidad: «Es un poco lo que pasa con un hijo, que te cuesta mucho sacrificio. Pasas malas noches por cuidarlo, pero en cuanto le ves la cara ya no te importa no haber dormido. Se ríe, te toca la mano y ya estás compensada. Pues en menor escala esto es lo mismo» (Joaquina, cincuenta y tres años, ANDE, discapacitados físicos). La mención del sacrificio, un valor que se ha convertido en anatema para el lenguaje primario (que lo entiende como perversión —el tan mencionado «masoquismo»-), transforma la noción de «compensación».

Ésta queda extraída de la lógica económica y aparece en su sentido original, que está siendo olvidado. El Diccionario de la Real Academia Española define «compensar», en su primera acepción, como «igualar en opuesto sentido el efecto de una cosa con el de otra». (Ése es el sentido en el que no dormir «compensa» por ver la sonrisa del hijo; también el esfuerzo del voluntario con el progreso del ayudado o la gratitud que éste muestra.) Sólo en su segunda acepción «compensar» es «dar alguna cosa o hacer un beneficio en resarcimiento del daño, perjuicio o disgusto que se ha causado», y en esta definición vemos cómo prima la intención de reequilibrio sobre el sentido económico del acto. El hecho de que tendamos a entender la compensación en un sentido meramente 
económico (ahora hasta las víctimas de accidentes o de la afición al fumar piden «compensaciones» a instituciones públicas o a empresas privadas) muestra el traspaso de vocabularios desde el dominio de lo económico al de lo moral.

Además de la curiosidad, la modestia y la entrega, el voluntario cristiano se caracteriza por «tener un talento o un carisma especial», algo que se relaciona explícitamente con la vocación, identificada tanto con «una llamada» como con «un camino». Ambos aluden a una naturaleza especial de carácter moral que induce al amparo y que está impelida por el cumplimiento de un objetivo extraindividual. La vocación como llamada conecta con el seguimiento de un ejemplo moral tanto más fuerte como cercano esté al voluntario. (Un sacerdote admirado en el colegio, una madre dedicada modesta y continuamente a la ayuda al extraño surgen, entre otros, como referencias de rol entre los voluntarios cristianos jóvenes). Por su parte, la vocación como camino entiende la vida como un relato con sentido orientado al compromiso. Nada que ver con la justificación del voluntariado como una «actitud» personal o como consecuencia de una elección subjetiva entre «diferentes opciones». La vocación, en un sentido fuerte que está ya en desuso, entronca con la caridad como eje axial del discurso cristiano, que conviene analizar en detalle.

A partir de las acepciones de los diccionarios generales, la caridad se puede entender como virtud, como sentimiento y como acción. En tanto que una de las tres virtudes teologales, se define como «el amor a Dios sobre todas las cosas y al prójimo como a uno mismo», remitiendo a un imperativo externo que ordena el amparo al otro. Así, «porque Dios lo manda y punto» es una motivación suficiente para el voluntariado cristiano. En tanto que sentimiento, la caridad es «el impulso a auxiliar con dádivas, cuidados y consuelos a quien lo necesita», tal como reza el Diccionario de María Moliner. La caridad es también una acción, «la limosna o socorro que se da a otro», tal como recoge el Diccionario de Manuel Seco, que asimismo da cuenta de la acepción más actual de actitud, en tanto que «disposición que se tiene a ayudar al prójimo». Frente a la virtud antigua de la amistad, intrínsecamente vinculada a la acción del zoon politiko en la polis el amor cristiano se extiende a todos los semejantes y constituye el vínculo principal de la comunidad religiosa: «Hay que querer al prójimo porque es lo que Dios manda» (Carmen, sesenta años, San Vicente de Paúl, mendigos). El mandamiento principal se sigue a través de la práctica, que en ocasiones se verbaliza como praxis social: «A lo largo de la historia los que han durado más en el compromiso solidario son los que siguen el Evangelio (...) En España iquiénes sacaron a los presos a la calle en tiempos de Franco? A quién más que a la Iglesia le importaban los drogados y los maricones? Querer al marginado es cosa del Evangelio: es tan contra natura que si no es por Dios, eso no dura. El amor sin retorno, eso es la auténtica caridad. Y el retorno no lo da el pobre que tiene SIDA, sino Dios, que te da esa paz por dentro» (Jaime Garralda, sesenta años, Horizontes Abiertos, presos). Entre los cuatro sentidos que destaco, me centraré en la caridad como 
virtud, que entronca con la compasión como sentimiento moral clave del lenguaje secundario.

Si echamos la vista atrás hacia los clásicos tras el análisis de la empatía de Adam Smith aparece Jean-Jacques Rousseau como analista de la compasión o lo que él llama pitié. Según Jean-Jacques Rousseau, la compasión es la repugnancia natural a ver sufrir a un semejante. Así la define en el Discurso sobre el origen de la desigualdad entre los hombres, donde conecta la pitié con el instinto de conservación o «amor de sí». Puesto que dicha compasión la tienen no sólo los hombres, sino también algunos brutos como los caballos (que se contienen antes de atropellar a otra criatura), la piedad, con ser un universal humano, no pasa de ser un instinto de poco valor social. Más enjundia tiene la compasión tal como la trata Rousseau en Emilio, como una virtud que se templa en sociedad y que se encadena con el «amor propio», alrededor del cual giran todas las pasiones irascibles y odiosas. Por ejemplo, la envidia que, como la compasión, surge de comparar nuestra suerte y la de los demás. Esta tendencia a medirse con el otro es propia del hombre en sociedad. Mas es la sociedad moderna y su sociabilidad alambicada la que desarrolla plenamente la vanidad, un vicio que los críticos de la Ilustración y del universo del comercio deploraban.

Como Smith, Rousseau reconoce que nos es más fácil entender la pena del otro más que su alegría: «No está en el corazón humano ponerse en el lugar de las personas que son más felices que nosotros, sino de aquellos que son más de compadecer» ${ }^{11}$. Tal sería la primera máxima de la piedad. Pero el ginebrino añade a la teoría smithiana de la empatía y del espectador interno que la sostiene (la necesidad de ponerse en el lugar del otro para identificarse con él) el llamado principio de la comparación. La compasión supone una excursión imaginaria, una salida de nosotros mismos para posarnos sobre el otro que nos ofrece un sentimiento de alivio de nuestros males. Por ello «aunque el primer sentimiento que le golpea "a Emilio" es un objeto de tristeza, el primer retorno sobre sí mismo es un sentimiento de placer. Y viendo de cuántos males se libra, se siente más feliz de lo que hubiera imaginado: comparte las penas con sus semejantes pero ese acto de compartir es voluntario y dulce» ${ }^{12}$. A través de esta comparación la compasión sobrepasa de alguna manera su condición de sentimiento moral (y desde luego de instinto, tal como era en el segundo Discurso) y deviene una especie de razón sensitiva que conecta con nuestro yo más íntimo. Mientras que el primer movimiento de la compasión es el vuelo desde nuestra intimidad a la exterioridad doliente del otro, el segundo movimiento es ese retorno a nosotros mismos, y supone el encuentro con un yo fortalecido por la conciencia de estar mejor que el compadecido: «Goza a la vez de la piedad que tiene por sus males y de la alegría de saber que

${ }^{11}$ J. J. Rousseau, Emile, en Oeuvres Complètes, vol. IV, París, Gallimard, Bibliothèque de la Pléiade, 1969, p. 506.

${ }^{12}$ Op. cit., p. 514. 
no los tiene; se siente en ese estado de fuerza por el que nos extendemos más allá de nosotros mismos y que nos hace llevar fuera de nosotros una actividad superflua y sobreabundante.» El principio de la comparación se observa en el relato de un voluntario joven que resalta el contraste entre la situación del joven y del mendigo al que ayuda: «Te ven como a un pardillo que, al final, se va a ir a su casa a dormir. Y es normal; yo no me tengo que levantar a las siete para ir a buscar una tarjeta desde el centro a la Plaza de España, hacer cola, luego ir al comedor y pasar la tarde por ahí durmiendo en unos cartones»(Aurelio, veinte años, Calor y Café, mendigos). Aquí se expresan la dificultad de la comprensión smithiana de la situación y el «retorno» rousseauniano a una realizad propia más segura y placentera que la del otro.

La segunda máxima de la piedad es que uno sólo se compadece de las desdichas de las cuales no está exento. Es decir, que la proximidad emocional con el que sufre se produce a través de la anticipación del infortunio. En este sentido el discurso cristiano se refiere explícitamente y sin rubor a lo que rodea la vejez: soledad, decadencia física, deterioro mental, dolor, muerte. (Toda una batería de experiencias que el voluntariado joven tiende a soslayar, entre otras razones porque prefiere centrarse en colectivos de ayuda que supongan un gasto productivo. En este sentido, los inmigrantes, los presos o los niños ofrecen un voluntariado «con futuro», es decir, una acción que pueda llevar a cabo la enseñanza de esa autonomía tan valorada y ofrecer la salida de la condición de excluidos). Por el contrario, la ayuda a colectivos como mayores o enfermos es un gasto improductivo, pero entronca con el propio futuro y con la más profunda condición humana. Si la compasión prende con los males que uno puede contraer, sin duda la vejez y las enfermedades activan aquélla.

La tercera máxima de la compasión rousseauniana es que ésta no se mide por la desgracia que le sucede al otro, sino por el sentimiento que se atribuye al sufriente. Es decir, que sólo nos condolemos por nuestros semejantes, por los que nos son más próximos o más parecidos. De ahí que la juventud — también la solidaria- resulte insensible ante las desdichas de los mayores, por carecer de experiencia acerca del final de la vida. (Quizá por ello los jóvenes voluntarios no entiendan las carencias de los más desvalidos, mientras que las mujeres de mediana edad saben comprender lo que es un viejo o un enfermo de Alzheimer, familiarizadas en su propia casa con la fragilidad extrema.)

Si la compasión no es un instinto, sino - tal como afirman Smith o Rousseau - que es algo que tiene lugar en sociedad cabe pensar que puede ser educada y convertida en una virtud que mejore la sociabilidad. Para desarrollar una paideia de la compasión, de esa «beneficencia activa» rousseauniana, habría que superar, a mi juicio, el mandato de la educación en la autonomía, que engendraba la desaparición de la necesidad, la negación por parte del voluntario de que el otro me necesita. Algo que produce una fuerte disonancia cognitiva en los colectivos donde la necesidad es más visible, como sucede con los men- 
digos y los ancianos. Frente a la independencia, una cultura compasiva ha de reconocer la necesidad genérica de los hombres y el valor de la interdependencia. En segundo lugar, una defensa sociológica (y no meramente psicológica) de la compasión precisa recuperar el sentimiento moral de la gratitud, desterrada en una cultura individualista que sospecha de los actos que se salen de una lógica económico-utilitaria que cifra en el interés la razón última de toda acción social, incluida la ayuda a los extraños. (De ahí la recesión del lenguaje secundario, que alude a horizontes externos — «la obediencia al Evangelio», «porque Dios lo manda», "por sentir el reconcomio ese interno que me dicta que debo ayudar»- frente a la prepotencia del primario, que alude a preferencias subjetivas.) Recuperar la gratitud supone apreciar el don del voluntario -en tiempo y en esfuerzo emocional- y en este reconocimiento abrir la posibilidad de forjar un vínculo duradero. Algo que impiden las organizaciones de la ayuda, que entienden el voluntariado como una ayuda durante un tiempo limitado, al modo de una rehabilitación terapéutica que no debe convertirse en hábito. Lo propio del paciente es pasar luego a un gimnasio donde fortalecer sus músculos, no caer en la dependencia de una comunidad de enfermos.

Aunque el discurso cristiano subraye el lenguaje secundario, hay que señalar que no deja de manifestarse entre los voluntarios cristianos una caridad mixta donde aparece la huella del individualismo: «Frente a la gente que lo hace por altruismo o por la humanidad yo lo hago por Dios y ello es muy gratificante.» La alusión a lo «gratificante» indica la fuerza del expresivismo y de la autorrealización como motivación principal de la ayuda. La naturaleza híbrida del discurso cristiano se avista también cuando se quiere negar el sacrificio, noción anatema en nuestra cultura, que niega la acción altruista si no está mezclada de razones egoístas: «Es más duro cuidar a tu padre, vamos, es otra película. Digamos que tú estás en el cine y que la película dura tres horas, pero se te pasa la película y te vas a casa. O sea, que de sacrificio nada» (Elena, cincuenta y tres años, Horizontes Abiertos, presos). La metáfora de la ayuda como una película subraya tanto el desdén por la idea de la entrega como la insistencia sobre el carácter parcial de la dedicación del voluntariado. Lo primero se puede hacer desde un razonamiento puramente utilitario, más chocante si proviene de una cristiana con una edad que no debería estar contaminada por la lógica economicista: «Somos lo suficientemente egoístas para aparcar lo que no nos satisface. Luego si "el voluntariado" te satisface es que no es duro. Así de fácil» (Rosa María, cincuenta y tres años, Nuevo Futuro, Rastrillo). Es decir, algo que te hace sentir bien se interpreta no en clave moral, como el cumplimiento de un deber, o como resultado de ese altruismo de participación que mencionaba más arriba y que puede dar lugar a la extensión de la responsabilidad. El bienestar interno se entiende aquí no en clave moral, como fruto de una acción virtuosa, sino en clave psicologista.

Pero en general, desde el lenguaje secundario los actos de compasión resultan en un amparo sostenido y duradero: el voluntario se convierte en sostén 
del necesitado. Resurge el valor de la dependencia como consecuencia de la fragilidad humana, algo que la cultura individualista niega, empeñada en dar soluciones a todos los problemas. Para aquélla, quien no es feliz o al menos está razonablemente satisfecho es un neurótico, alguien que no sabe gestionar su capital psíquico y que debe consultar a los expertos en tecnologías del yo. La infelicidad, el dolor, la enfermedad o la soledad son tabúes en un clima de banalidad o «euforia perpetua» ${ }^{13}$ propia de individuos que sólo se atribuyen responsabilidad sobre sí mismos, en lo que llamo una responsabilidad reflexiva que al mismo tiempo que se desentiende del compromiso con los demás arroja sobre sí toda suerte de deberes. Pero, más allá del lenguaje primario, pienso que la compasión enlaza con la responsabilidad como «hacerse cargo» ${ }^{14}$. La expresión significa, en una de sus acepciones, «un reparto del mundo», una aceptación de la comprensión que el otro precisa y reclama. En este sentido, pienso que la responsabilidad laica y racional se enlaza naturalmente a la compasión cristiana.

Ésta está compuesta de tres sentimientos morales: la aflicción por el mal ajeno, la condolencia o participación en la desgracia del otro, y la conmiseración o malestar producto de la miseria del otro. Esta «entrada en el otro», por decirlo así, supone una intensidad sentimental impensable desde la psicología fría del lenguaje primario individualista. En los grupos de discusión se cuenta cómo en San Vicente de Paúl los ancianos se sienten «amparados en la sede, cómo se ha tratado de hacer de ella un lugar cómodo y caliente donde siempre se ofrezca compañía». No se alude aquí a las consignas de las ONG modernas, como la distancia de rol y a la necesaria brecha temporal que los voluntarios deben aceptar - a riesgo de enfriar su impulso solidario - entre el momento en el que llegan y cuando comienzan su labor. Al contrario, las voluntarias de organizaciones cristianas tradicionales dan rienda suelta a relatos emotivos que hablan de una compasión en su sentido original y moralmente fuerte: «Le llevé a la anciana la foto del barrio en el que vivía, Chamberí, y se puso muy contenta, la pobre. Son cosas pequeñas pero que a ella le ayudan» (Carmen, sesenta años, San Vicente de Paúl, ancianos).

El peso de la caridad como un hábito virtuoso, tal como sostiene la teología tradicional y repiten los participantes, «requiere un ejercicio constante, porque, si no, se te olvida», como si fuera un deporte que hay que practicar. Intromisiones de la metáfora deportiva del modelo del crecimiento. Con todo, el discurso cristiano se articula alrededor del altruismo exocéntrico, dirigido a aumentar el contento del otro, y de razonamientos morales que explican la ayuda organizada. Tal es el caso de la alusión a la deuda.

${ }^{13}$ La feliz expresión es de Pascal Bruckner que analiza crítica y lúcidamente cómo el ideal de felicidad se ha convertido en un imperativo a la vez coercitivo y trivial. Al respecto véase La euforia perpetua. (Sobre el deber de ser feliz), Barcelona, Tusquets, 2001.

${ }^{14}$ Para un análisis sucinto y atractivo de la idea de responsabilidad puede verse la obra de M. Cruz, Hacerse cargo. (Sobre responsabilidad e identidad personal), Barcelona, Paidós, 1999. 
Tanto en los jóvenes cristianos entrevistados como en las señoras que articulan el discurso tradicional se menciona el pago de una deuda simbólica como uno de los motivos del voluntariado. Éste sería una especie de pago que se hace por los dones - sociales y personales - recibidos. Ayudar a un extraño supone, así, pagar una deuda contraída con Dios a través de la ofrenda que uno hace de sí a otro. Entendiendo la vida como una hoja de doble entrada «cuyo saldo puede ser positivo o negativo», los actos de compasión aparecen en la columna de los ingresos: «A mí sí me preocupan las cuentas que Dios me vaya a pedir ahí arriba. Que a lo mejor es que no he hecho nada por los demás y lo hubiera tenido que hacer» (Paloma, sesenta y cuatro años, Nuevo Futuro, menores). Pero la deuda puede tenerse no sólo con Dios, sino también con los próximos a quienes no se cuidó; en ese caso el auxilio a un extraño supone un desplazamiento pospuesto del cuidado debido. En adelante se cuidará de los extraños como si fueran próximos, es decir, se ampliará una conciencia de ayuda o una caridad expansiva que produce simultáneamente una regeneración moral propia y una extensión social del don. Se retoma así el modelo del intercambio y se refuerza la defensa sociológica de la compasión. Asimismo, se esboza una noción de libertad que no es libertad de elección (entre «opciones» de igual valor - como defiende el expresivismo individualista-) ni libertad negativa - frente a-, sino, por el contrario, una libertad «hacia» un ideal que subraya la conexión y no la independencia.

Tal como sugería Rousseau, la compasión produce una «expansión del ser», un deleite natural por la conciencia de la ayuda. Pero este contento no se da, entre los voluntarios cristianos, en clave psicológica - como gratificación interna—, sino moral — como acuerdo de la voluntad y la obediencia al precepto de la caridad-. Para amar al prójimo se ha de tener una sobreabundancia de fuerzas que confiere la fe. En clave laica la conmiseración supone una energía sobreabundante: «Para compadecer el mal de otro sin duda hay que conocerlo pero no sentirlo. Cuando se ha sufrido o cuando se teme sufrir, uno se compadece de quienes sufren, pero mientras que se sufre, uno no se compadece más que de sí mismo» ${ }^{15}$. En clave cristiana, la sobreabundancia de fuerzas que construye la virtud de la caridad roza con el vicio del orgullo: «Me importa la gente. Y aguanto muy bien que sufra sin poder yo pegar un grito. Si no cambio su situación, al menos estoy ahí. Porque me importa mirar mi vida en profundidad» (Jaime Garralda, setenta años, Horizontes Abiertos, presos).

La práctica de la fraternidad cristiana descansa asimismo en el valor de la esperanza, acicate para la construcción de una Vida Buena. Este sentimiento moral despega del horizonte temporal presentista del lenguaje del individualismo y entronca con la comprensión del voluntariado como un comportamiento ejemplar.

\footnotetext{
${ }^{15}$ Rousseau, op. cit., p. 514.
} 
El cristianismo confiere una seguridad interna unida a la alegría que da la fe activa y fructuosa: «Cuando en ámbitos muy desesperados surge la esperanza, es para comerse el mundo. Descubrir que hay un último hálito para seguir adelante, a pesar de todo, es una pasión. La historia de la Biblia es la de las cosas cambiantes. La verdad última es que es imposible que las cosas no cambien a mejor. Y si no ganamos nosotros no gana nadie» (Jaime Garralda, setenta años, Horizontes Abiertos, presos). El discurso cristiano subraya esa esperanza que hace del voluntariado una muestra del progreso moral de la humanidad. Algo que el lenguaje primario de los jóvenes sólo aceptaba con reservas, insistiendo en la aportación de «un grano de arena», modesto y limitado. Frente a estos reparos, el lenguaje secundario insiste en la metáfora de la cadena de ayuda, una cadena con una peculiar aleación en los tiempos modernos.

\section{Las tensiones del discurso cívico}

Dícese que el voluntariado es un puente tendido entre el individualismo liberal, de un lado, y la participación cívica, por otro. Su prestigio revive la dimensión ética de la actividad social, la implicación en la esfera colectiva, la toma de conciencia de la desigualdad y la exclusión del prójimo. El voluntariado recupera la confianza que ha perdido el Estado y la política clásica de los partidos, asociada a la burocracia esclerotizada y al carrerismo corrupto. Pero icuáles son los títulos de este voluntariado que merecen tanto crédito? He buscado en la versión laica del discurso secundario. Para ello analicé el discurso de un voluntariado minoritario (frente al de los jóvenes, que es el mayoritario) y nuevo (frente al tradicional de las mujeres de mediana edad cristiana). Éste se puede encontrar en las llamadas generaciones cívicas. Tomo el concepto de Robert Putnam ${ }^{16}$ y amplío los límites de dicha generación (que él cifra en el grupo de edad que nace alrededor de 1930) para analizar el grupo de edad entre treinta y cinco a cincuenta y cinco años. En dicho estrato buscaba un discurso cívico y progresista, que articulara la ayuda como una empresa no sólo moral - como creen los cristianos-, sino también colectiva. Es decir, una concepción del mundo cívica, orientada a la participación en la esfera pública y crítica con el individualismo liberal, y progresista, que girara en torno a la política de la emancipación (frente a la política de la vida que ensalzan los jóvenes), a la igualdad como meta moral (no a la «exclusión», que ha sustituido en el lenguaje común a aquélla), al cambio político como transformación de las estructuras (no sólo a la mudanza moral hacia una mayor «sensibilización» o tolerancia hacia el otro). Veremos que tal discurso brilla

${ }^{16}$ Ver R. D. Putnam, «The strange disapearance of civic America», The American Prospect, núm. 26, invierno de 1996, pp. 34-48, y «Democracy in America at century's end», en A. Hadenius (ed.), Democracy's Victory and Crisis, Cambridge University Press, 1997. 
por su ausencia y que, del mismo modo que entre los jóvenes voluntarios el espontaneísmo sustituía a la conciencia de pertenencia a una organización que forma parte de una sociedad política transformadora, entre los maduros profesionales se combinan un realismo de corte individualista y un voluntarismo de raigambre cívica.

Alguien señala que el voluntariado entre los profesionales tiene que ver con tener tiempo libre. Condición necesaria en todo el altruismo democrático, en este caso cobra una relevancia especial porque se trata de un tiempo sobrante que hace de la ayuda una actividad secundaria y sustitutoria. Lo que se reemplaza es la dedicación a la profesión con miras a conseguir el éxito. Es decir, el voluntariado no es tanto una actividad cívica para un grupo de edad que podría tener una experiencia pasada de implicación en lo colectivo (en partidos políticos o en el movimiento ciudadano) como la coartada del fracaso profesional. En efecto, se dice que la ayuda a los extraños se lleva a cabo «cuando se tienen otros planos a cubierto», siendo éstos la vida privada y el trabajo, que apuntan a ámbitos de significación primordial. Así, si buscábamos un lenguaje cívico que insistiera en la prioridad de lo público, encontramos que es la esfera privada (el ámbito de los afectos) y la llamada esfera social (según Hannah Arendt), la de la profesión, las que precisan de atención primaria. Lo demás viene después. Se repite aquí algo que ocurría entre los jóvenes, esto es, la desvalorización de la ayuda por parte de los propios voluntarios. Pero si entre los jóvenes ello obedecía a una política organizativa mal entendida, que prima el rol y el distanciamiento frente a la unicidad y la implicación social y emotiva, entre los profesionales la relativización de la actividad voluntaria viene por el reconocimiento de que las fuentes de identidad están en otra parte: «En mi organización solemos hablar de las dos des: el perfil del voluntario es el de un Divorciado y un poco Desequilibrado, al menos en su vida social» (Arturo, cuarenta y cinco años, Arquitectos sin Frontera, cooperación al desarrollo). Lo principal es realizarse en lo privado y en el ámbito del mercado, tal como reza el imaginario liberal. Es más: tal aserto queda sin réplica, algo curioso para quienes - algunos al menos - tienen un pasado de implicación con lo colectivo. Lo crucial en la desvalorización de la ayuda, y en su adelgazamiento como una práctica cívica, es su parentela con el fracaso: «En la Escuela te forman como si fueras el número uno y pudieras hacer grandes proyectos. Y luego te das cuenta de que te has quedado haciendo chalecitos o en una constructora firmando certificaciones de edificación. Tienes cincuenta años y algo tienes que hacer... así que te dedicas al voluntariado.»

Mientras que en el discurso cristiano aparecía la metáfora de la deuda, en el de los profesionales se subraya la idea de interdependencia como materia de un don que fluye libre y gratuitamente, dentro de un intercambio que articula los lazos sociales: «Siempre he pensado que si yo tengo algo lo comparto y si otro lo tiene lo comparto también. Nunca he tenido reparo en que si alguien tiene algo y me lo ofrece, aceptarlo, y nunca he sentido que ni la 
otra persona ni yo tuviéramos que estar en deuda. A mí me han ofrecido dinero cuando vivía con muy poco y lo he aceptado, sin sentirme mal por eso. Y con el mismo espíritu hago esto: si yo tengo la oportunidad de hacer algo y el otro otra cosa, pues eso» (Mariví, cincuenta años, Médicos Mundi, gabinete de psicología con inmigrantes). Así, la solidaridad tiene que ver con ese compartir que, en su normalización, se espesa y se hace hábito moral, comportamiento natural. La ayuda al extraño se convierte en una costumbre, en una práctica cívica ligera, libre de religión e ideología.

Los profesionales insisten en la socialidad de mezcla — de clases y de edadque promueve el voluntariado, algo que crea un comunitarismo estimulante que detrae de la tendencia al privatismo. El altruismo organizado impulsa asimismo el ejercicio de la deliberación de problemas comunes, dando lugar a lo que Hannah Arendt llama «natalidad», un sentimiento de poder grupal hecho de proyectos y de entusiasmo público. En esta misma línea, el voluntariado se entiende como intervención en la vida de los otros y en la sociedad en su conjunto: «Me interesa que las mujeres del taller sepan que pueden salir del medio estrecho en el que viven: su marido, su cocina y sus hijos. Entre todas aprendemos que todavía hay tiempo y oportunidades» (María, cincuenta y cinco años, taller con mujeres). Nada que ver con la visión de la ayuda como consecuencia de preferencias subjetivas, como se explicaba desde el emotivismo de los jóvenes.

$\mathrm{Y}$, sin embargo, el lenguaje secundario aparece teñido de individualismo. Ello se observa en las referencias al estilo de vida. El voluntariado, se dice, dejará de tener con el tiempo el carácter de actividad extraordinaria y se integrará en una forma de vida civilizada. Formará parte de una sociedad civil que deja una franja horaria a la ayuda al extraño. Dentro de este progreso de la urbanidad cabe señalar dos sentimientos morales. En primer lugar, la confianza como clima moral de una sociedad liberal compleja. Mientras que las sociedades premodernas se tejían sentimentalmente alrededor de la fe - cristiana- o del entusiasmo - republicano-, la sociedad del comercio precisa de una racionalidad basada en predecir las relaciones sociales. El voluntariado normalizado, como una actividad cívica sin especial contenido moral, forma parte de este clima de confianza. El segundo sentimiento moral es el interés bien entendido, materia de una sociedad progresivamente privatizada. Dicho interés no es identificable con el egoísmo, sino con la comprensión de que la persecución del beneficio personal redunda en el bien colectivo. El interés bien entendido conecta el bienestar público con el hábito privado y contribuye a la extensión del capital social, es decir, al conjunto de redes sociales y reglas de reciprocidad o, lo que es lo mismo, a la capacidad de las personas para agruparse y organizarse con propósitos comunes ${ }^{17}$.

${ }^{17}$ Para el concepto de capital social véase la obra de James S. Coleman, Foundations of Social Theory, Harvard University Press, The Belknap Press, 1990. Y desde luego Making Democracy Work. (Civic traditions in modern Italy), Nueva Jersey, Princeton University Press, 1993. 
Los profesionales avisan de la ausencia de virtudes cívicas dentro de las organizaciones de la filantropía democrática. Así, de la autodisciplina, necesaria para persistir en el compromiso; pero el voluntariado de los jóvenes es efímero y volátil. También se echa de menos la lealtad, sentimiento moral necesario para conectarse de manera profunda a la sociedad; pero los jóvenes están animados por un voluntarismo que se agota entre la maraña burocrática o el coste que supone una ayuda sostenida. Frente a los «buenos sentimientos» o al «redentorismo» las ONG tendrían que crear y mantener el sentimiento de pertenencia asociativa.

Como en la versión cristiana del lenguaje secundario, en la versión laica de un civismo mixto surge la virtud de la esperanza. Materia de una defensa sociológica de la compasión, la esperanza tiene afinidades con la interdependencia, cemento de una solidaridad responsable. Alguien compara la contribución del voluntariado con el poso que deja la enseñanza en los buenos alumnos, una herencia que se ve sólo a largo plazo. Otra metáfora poderosa es la de la «broca, que poco a poco puede hacer un hueco en la piedra». Pero la esperanza no se alimenta del aire. Los voluntarios más comprometidos socialmente, con más años de experiencia en la brega ciudadana, aquellos que no se dejan mecer por ese escepticismo post-ideológico del ex militante y hoy voluntario, ven moverse el suelo bajo sus pies. No avistan el fin de una cultura moral centrada en el indivualismo posesivo y privatista, ni el remedio al imperio normativo de la autosuficiencia en unas instituciones cívicas poco desarrolladas. Pero no acaban de articular un lenguaje moral alternativo.

Javier, de cuarenta y cinco años, es a la vez voluntario en una pequeña asociación de barrio y responsable de voluntariado de Médicos Mundi. Como voluntario explica la carencia de pertenencia asociativa por el trato que con los voluntarios tienen tanto los trabajadores sociales como los psicólogos. Mientras que los primeros son meros «ficheros de recursos humanos» los segundos «carecen de lenguaje social» y seguramente extienden ese individualismo que predica entre los jóvenes la autosuficiencia y la neutralidad valorativa. Pero como responsable de voluntariado respalda el distanciamiento que imponen las ONG: «El voluntario se tiene que implicar pero no diluirse. El encariñamiento produce dependencia.» Javier acaba siendo presa de esa ambivalencia moral que recorre el discurso de los profesionales. Si se niega el sentimiento como combustible del voluntariado y, a la vez, se reconoce el insuficiente sentido de pertenencia que las asociaciones generan, ¿cuál será el sostén de la filantropía democrática?

\section{Inconclusión}

Responderé a la pregunta formulada resumiendo los argumentos expuestos. Desde la defensa psicológica de la ayuda a los extraños el sostén de la nueva filantropía es muy débil. El altruismo endocéntrico da lugar a un voluntariado 
inestable que presta ayuda para sentirse bien. Se supone que una vez logrado dicho objetivo el voluntario puede abandonar su tarea y dedicarse a cualquier otra actividad que forme parte de su estilo de vida. Aunque también se puede pensar que, si uno se siente bien ayudando a los demás se puede prolongar este acto. Tal como se incorpora a la cotidianeidad la gimnasia del cuerpo, también se puede hacer un hueco para el ejercicio del alma, mejor dicho, de los propios deseos, desde el emotivismo imperante. La duración de tales ejercicios es cosa difícil de prever. Más preocupante a efectos sociales es la idealización de que goza todavía el voluntariado entre los jóvenes. Carentes de un lenguaje político que articule aquél en una práctica cívica, los voluntarios caen presa de un espontaneísmo que entiende la ayuda a los extraños como un buen impulso que debe permanecer libre, sin sujeciones organizativas. Dicho espontaneísmo es la enfermedad infantil de la participación y enlaza con la paradoja irónica: la desconfianza institucional respecto a la esfera pública redunda en una desvalorización de la imagen del propio voluntario, «primo» ante un Estado que se aprovecha de su buena voluntad o «gorrón» que quiere sacar provecho de las insuficiencias de aquél. Por otra parte, el predominio del lenguaje individualista da lugar a la paradoja trágica: el valor de la autosuficiencia más el ideal de libertad negativa y sus sentimientos morales fríos producen la desaparición de la necesidad. Si todos somos iguales en potencialidades y a la vez todos debemos proteger nuestro espacio, ia quién se cuida y desde qué mínima implicación afectiva? Si el otro a quien se ayuda es sólo portador de un servicio a horas fijadas, carece del peso moral de ser víctima de una situación social de desigualdad o injusticia. Es más bien un ser distinto merecedor de tolerancia, mas no de compasión. Así, el distanciamiento que enseñan las ONG no sólo se aplica al objeto de ayuda, sino también a la comprensión social y política de la realidad. La suspensión del juicio sobre quiénes o qué ha puesto en esa situación a los merecedores de ayuda lleva consigo una visión psicomórfica del mundo que hace de la ayuda una elección puramente subjetiva, desenraizada de la conciencia social y la práctica cívica.

Sin embargo, más allá del emotivismo del lenguaje primario, cabe una defensa sociológica de la ayuda, tanto en clave cristiana como laica. La primera aparece, empero, mucho más clara en los discursos. Los voluntarios cristianos expresan un altruismo exocéntrico que parece duradero al defender un sentido fuertemente moral de la compasión como un sentimiento moral caliente que supone sufrir con el extraño que ya no es un Otro al que se debe tolerancia, sino un prójimo al que se ama, al que se presta una caridad fraternal. Si nos deshacemos de prejuicios antirreligiosos podremos entender la caridad como la base de un altruismo democrático duradero. La identificación profunda con el otro puede dar lugar a lazos profundos que trasciendan la distancia de rol que imponen las ONG. Desde una comprensión de la situación personal y social del otro ayudado puede tener lugar una empatía duradera. Dicha 
defensa sociológica es compatible con el modelo del intercambio: el voluntariado es un don que retorna con la gratitud - sentimiento moral a recuperar- o con la conciencia de haber transformado parte de la vida del otro. Pero el retorno simbólico del don ha de ir apoyado, además de por sentimientos fuertes que incluyan la conciencia de fragilidad genérica y por ende de la recuperación del valor de la interdependencia, de instituciones apropiadas.

Desde una defensa laica y sociológica de la compasión hay que recordar que las instituciones pueden ser enclaves de virtud cívica. La parroquia - tan importante para el voluntariado cristiano-, las asociaciones de barrio y los colegios se citan como lugares donde prende la chispa del altruismo. Son también ámbitos donde se espesa la densidad moral. Ya lo decía Emile Durkheim: la felicidad personal depende sobre todo de la red de vínculos sociales que tenga el hombre. Si el contento personal entronca con el progreso del bienestar general se produce lo que Tocqueville llamaba el interés bien entendido. Éste es un sentimiento moral que no tiene la fuerza emotiva de la compasión ni de la caridad, pero que templa el individualismo de nuestros contemporáneos. Dicho interés puede ser otra de las bases emocionales del voluntariado en una sociedad progresivamente privatizada en la cual ya la ayuda a los extraños se convierta en parte del estilo de vida. Para ello hace falta que la cultura política extienda el sentido de la responsabilidad, trasunto de la solidaridad del discurso emancipatorio. De nuevo, hay que mencionar a las instituciones como centros de esa responsabilidad ciudadana. Las ONG deberían ser foros de deliberación de problemas sociales más que centros de expansión de una cultura individualista. Es necesario que un ideal de libertad «hacia» sustituya al de la libertad «frente a»; construiríamos así una libertad cívica que sepa apreciar la capacidad de los individuos, sobre todo si se asocian, para conformar la sociedad política. A la vez, es tarea de los gobiernos extender a través de la educación una conciencia no sólo civilizada - propia de una sociedad civil urbanizada-, sino politizada. En el sentido aristotélico de la política. Desde un rescate del triángulo republicano compuesto por un buen gobierno que sea capaz de gestar unas leyes justas que, a su vez, transformen a los ciudadanos a través de las costumbres. De unas costumbres basadas en unos sentimientos morales cívicos. Pero eso es otra historia ${ }^{18}$.

\footnotetext{
${ }^{18}$ Para un estudio crítico sobre el origen y desarrollo hasta la actualidad de la tradición republicana puede verse mi libro El corazón de la república. (Avatares de la virtud política), Barcelona, Paidós, 2000
} 